\title{
The Impedance Properties Analysis of Composite Electrodes for Supercapacitor
}

\author{
Jin-Yan Song \\ School of Information Engineering \\ Dalian Ocean University \\ Dalian, China \\ thesjyyan@163.com
}

\author{
Xin-Ying Miao, Li-ying Hao,Ke-wei Cai \\ School of Information Engineering \\ Dalian Ocean University
}

\author{
Teng Gao \\ School of Mechanical Engineering \& Automation \\ Dalian Polytechnic University \\ Dalian, China \\ gaoteng@dlpu.edu.cn \\ Dalian, China \\ miaoxinying@dlou.edu.cn \\ haoliying@dlou.edu.cn \\ caikewei@dlou.edu.cn
}

\begin{abstract}
Supercapacitor can get high energy density and the ability of quick charging and discharging. In this work, the different mass ratios of composite electrodes mixed with active carbon (AC) based on $\mathrm{RuO}_{2} \cdot x \mathrm{H}_{2} \mathrm{O}$, were prepared to study the electrical performance parameters of the incorporations. Through Conway's model and impedance spectroscopy, the composite electrode model has been established, and it is validated by the experiments on their electrochemical performances for different proportions of composite electrodes fabricated with $\mathrm{RuO}_{2} \cdot x \mathrm{H}_{2} \mathrm{O}$ and active carbon. The simulation results show that the composite electrode with 60wt.\% amorphous hydrous ruthenium oxide has the lower inner resistance and the higher degree of ruthenium oxide utilization, which are testified by the experiments.
\end{abstract}

Keywords- Supercapacitor; Impedance; Spectroscopy; Equivalent Circuit Model; Mass Ratio

\section{INTRODUCTION}

Supercapacitors are widely used in pulse power source as energy storage element, due to their high-power density, long cycle life, and bridging function for the power/energy gap between traditional dielectric capacitors (which have been high-power output) and batteries/fuel cells (which have been high-energy storage)[1-3]. Currently, the electrode material research concentrated on the carbons [47], the transition metal oxide [8-10] and conducting polymers [11-13], which all have high specific capacitance in the electrolyte. Transition metal oxides such as ruthenium oxide $[14,15]$, manganese oxide [16], cobalt oxide [9], and nickel oxide [17], which have drawn extensive research attention as electrode materials, are qualified to be electrode materials for electrochemical capacitor. Ruthenium oxide exhibits excellent properties as pseudo-capacitive electrode materials. However, the expensive price restricts its wider applications [18]. In the ruthenium oxide mixed with other types of electrode materials is a commonly used method. As Mn [15], carbon [19], and Ti [20], and other types of electrode materials [21, 22] are incorporated in a common method of ruthenium oxide. So in the ruthenium oxide with these materials, the material quality in the whole electrode ratio on the electrical performance parameters of the electrode what effect? In this paper, the problem has been solved by established the equivalent circuit models, the element parameters of which were extracted by impedance spectroscopy. The different mass ratios $\mathrm{RuO}_{2} \cdot x \mathrm{H}_{2} \mathrm{O} / \mathrm{AC}$ composite electrodes have been prepared to obtain associated electrical properties of experimental parameters. Through simulation and experimental results, we obtain the relationships between the resistance and capacitance change with the mass ratio, the density and other basic parameters of the composite electrodes, such as to prepare corresponding composite electrodes in the different applications.

\section{EXPERIMENTS}

\section{A. Preparation of the electrodes and the samples}

The hydrous ruthenium oxide powder was formed by a Sol-gel process. Then hydrous ruthenium oxide and active carbon powder at the mass ratio $\alpha$ of hydrous ruthenium oxide in the composite electrodes mixed and skived equability that adding to the proper PTEF. According to the membrane preparation technology, pressed them into the thickness of $0.2 \mathrm{~mm}$ membrane, intercepted the dimension of $1 \times 1 \mathrm{~cm}^{2}$ membranes and pressed it on the tantalum foil current collectors. Then the two above uniform electrodes are separated by the fiberglass cloth, infused in the concentration of $38 \%$ vitriol electrolyte to compose of the symmetrical supercapacitor unit as the samples. When the mass ratio of hydrous ruthenium oxide in the composite electrodes $\alpha=0$, $0.1,0.2,0.3,0.4,0.5,0.6,0.7,0.8,0.9,1.0$, it fabricates 11 super-capacitors of the same thickness.

\section{B. The Performance Test of Composite Electrodes}

The equipment used in the experiments is mainly CHI660A model electrochemistry workstation. The experiment temperature is room temperature. 
Charging and discharging test are made for the above samples, the constant current of charging and discharging is $3 \mathrm{~mA}$, the range of charge and discharge voltage is $0-1 \mathrm{~V}$. According to the measured charge and discharge curve, it can obtain the specific capacitance of the composite electrodes:

Where $I$ is the discharging current; $\Delta t$ and $\Delta V$ are the time difference and voltage difference of corresponding discharging process respectively; $C_{\mathrm{p}}$ is the specific capacitor of single electrode in $\mathrm{F} / \mathrm{g} ; m$ is the average mass of two electrodes of super-capacitors.

Added a small magnitude sine AC signal on above samples with the frequency of $0.1 \mathrm{~Hz} \sim 100 \mathrm{kHz}$ and the voltage of $5 \mathrm{mV}$, measurement results can be gotten from Electrical Impedance Spectroscopy (EIS)

\section{MODELLING OF COMPOSITE ELECTRODES FOR SUPER-CAPACITORS}

Using kinetic parameters to create a supercapacitor equivalent circuit model is one of the main EIS analyses; it can compare the performance of the electrode kinetics intuitively [25]. At present, the common supercapacitor models mainly have a simple model of the ESR [26], Conway's model [27], transmission line model [28] and neural network model [29], etc. This article used the Conway's model to establish the model of the composite electrodes.

Conway established the equivalent circuit model of super-capacitor, as seen in Fig.1, where $\mathrm{R} \Omega, \mathrm{Rs}, \mathrm{Cd}$ and $\mathrm{Cs}$ represent lead and electrolyte resistance, rate constant, double layer capacitance and Faraday capacitance, respectively. The real part and imaginary part of impedance $\mathrm{Zi}, \mathrm{Zj}$ are respectively given by:

$$
\begin{gathered}
Z_{\mathrm{i}}=R_{\Omega}+\frac{R_{\mathrm{s}}}{\left(1+\frac{C_{\mathrm{d}}}{C_{\mathrm{s}}}\right)^{2}+\left(\omega C_{\mathrm{d}} R_{\mathrm{s}}\right)^{2}} \\
\text { and } Z_{\mathrm{j}}=\frac{\frac{1}{\omega C_{\mathrm{s}}}\left(1+\frac{C_{\mathrm{d}}}{C_{\mathrm{s}}}\right)+\omega C_{\mathrm{d}} R_{\mathrm{s}}^{2}}{\left(1+\frac{C_{\mathrm{d}}}{C_{\mathrm{s}}}\right)^{2}+\left(\omega C_{\mathrm{d}} R_{\mathrm{s}}\right)^{2}}
\end{gathered}
$$

Here $\omega$ is angle frequency. Capacitance can be calculated by:

$$
C(\omega)=\operatorname{Re} \underline{C}=\frac{\operatorname{Im} Y}{\omega}=\frac{-\operatorname{Im} Y}{\omega|Z|^{2}}=\frac{-\operatorname{Im} Z}{\omega\left[(\operatorname{Re} Z)^{2}+(\operatorname{Im} Z)^{2}\right]}
$$

where $Z, Y$ and $\underline{C}$ is the impedance, admittance and the complex capacitance, respectively.

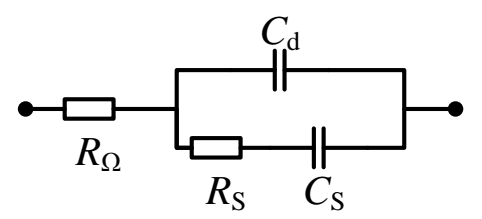

Figure 1. The Conway's model for supercapacitor

For $\mathrm{RuO}_{2} \cdot x \mathrm{H}_{2} \mathrm{O}$ /active carbon composite electrodes, when $\alpha=0$, it is pure active carbon electrode. The real part and imaginary part of impedance can be expressed in terms of Fig. 1 as:

$$
\begin{gathered}
Z_{\mathrm{iC}}=R_{\Omega \mathrm{C}}+\frac{R_{\mathrm{sC}}}{\left(1+\frac{C_{\mathrm{dC}}}{C_{\mathrm{sC}}}\right)^{2}+\left(\omega C_{\mathrm{dC}} R_{\mathrm{sC}}\right)^{2}} \\
\text { and } Z_{\mathrm{jC}}=\frac{\frac{1}{\omega C_{\mathrm{sC}}}\left(1+\frac{C_{\mathrm{dC}}}{C_{\mathrm{sC}}}\right)+\omega C_{\mathrm{dC}} R_{\mathrm{sC}}^{2}}{\left(1+\frac{C_{\mathrm{dC}}}{C_{\mathrm{sC}}}\right)^{2}+\left(\omega C_{\mathrm{dC}} R_{\mathrm{sC}}\right)^{2}}
\end{gathered}
$$

where $\mathrm{R} \Omega \mathrm{C}, \mathrm{ZiC}, \mathrm{ZjC}, \mathrm{RsC}, \mathrm{CdC}$ and $\mathrm{CsC}$ are the lead and electrolyte resistance, real impedance, imaginary impedance, double layer capacitance and Faraday capacitance of active carbon electrodes, respectively.

When $\alpha=1$, it is pure $\mathrm{RuO} 2 \cdot \mathrm{xH} 2 \mathrm{O}$ electrode. The real part and imaginary part of impedance are obtained from the following equations, respectively.

$$
\begin{gathered}
Z_{\mathrm{iRu}}=R_{\Omega \mathrm{Ru}}+\frac{R_{\mathrm{sRu}}}{\left(1+\frac{C_{\mathrm{dRu}}}{C_{\mathrm{sRu}}}\right)^{2}+\left(\omega C_{\mathrm{dRu}} R_{\mathrm{sRu}}\right)^{2}} \\
\text { and } Z_{\mathrm{jRu}}=\frac{\frac{1}{\omega C_{\mathrm{sRu}}}\left(1+\frac{C_{\mathrm{dRu}}}{C_{\mathrm{sRu}}}\right)+\omega C_{\mathrm{dRu}} R_{\mathrm{sRu}}^{2}}{\left(1+\frac{C_{\mathrm{dRu}}}{C_{\mathrm{sRu}}}\right)^{2}+\left(\omega C_{\mathrm{dRu}} R_{\mathrm{sRu}}\right)^{2}}
\end{gathered}
$$

Here $\mathrm{R} \Omega \mathrm{Ru}, \mathrm{ZiRu}, \mathrm{ZjRu}, \mathrm{RsRu}, \mathrm{CdRu}$ and $\mathrm{CsRu}$ are the lead and electrolyte resistance, real impedance, imaginary impedance, double layer capacitor and Faraday capacitor of pure $\mathrm{RuO} 2 \cdot \mathrm{xH} 2 \mathrm{O}$ electrodes, respectively.

The super-capacitor made in $\mathrm{RuO} 2 \cdot \mathrm{xH} 2 \mathrm{O} / \mathrm{C}$ composite electrodes at $\alpha=0 \sim 1$ also satisfies the model in Fig.1. As the active carbon and $\mathrm{RuO} 2 \cdot \mathrm{xH} 2 \mathrm{O}$ particulate in the process do not affect their properties, $\mathrm{RuO} 2 \cdot \mathrm{xH} 2 \mathrm{O}$ and active carbon do not influence each other. The electrolyte concentration is assumed to be invariant and side reactions and thermal effects are ignored, the electrolyte resistance is invariant. To remove the part of electrolyte resistance, the equivalent circuit of composite electrodes could be seen as two capacitors of pseudo-capacitor from $\mathrm{RuO} 2 \cdot \mathrm{xH} 2 \mathrm{O}$ and double layer capacitor from active carbon in parallel. Therefore the equivalent circuit can be seen in Fig.2, where R $\Omega f$, Rsfc and $\mathrm{RsfRu}, \mathrm{CdC}$ and $\mathrm{CdfRu}, \mathrm{CsfC}$ and $\mathrm{CsfRu}$ are lead and electrolyte resistance of composite electrodes, rate constant of active carbon and $\mathrm{RuO} 2 \cdot \mathrm{xH} 2 \mathrm{O}$, double layer capacitors and pseudo-capacitors of active carbon and $\mathrm{RuO} 2 \cdot \mathrm{xH} 2 \mathrm{O}$, respectively. From Fig.2, it can be seen that the resistance and reactance of the first and second branch are separately written as:

$$
\begin{gathered}
Z_{\mathrm{ifc}}^{\prime}=\frac{R_{\mathrm{sfC}}}{\left(1+\frac{C_{\mathrm{dfC}}}{C_{\mathrm{sfC}}}\right)^{2}+\left(\omega C_{\mathrm{dfC}} R_{\mathrm{sfC}}\right)^{2}} \\
\text { and } Z_{\mathrm{jfc}}^{\prime}=\frac{\frac{1}{\omega C_{\mathrm{sfC}}}\left(1+\frac{C_{\mathrm{dfC}}}{C_{\mathrm{sfC}}}\right)+\omega C_{\mathrm{dfC}} R_{\mathrm{sfC}}^{2}}{\left(1+\frac{C_{\mathrm{dfC}}}{C_{\mathrm{sfC}}}\right)^{2}+\left(\omega C_{\mathrm{dfC}} R_{\mathrm{sfC}}\right)^{2}} .
\end{gathered}
$$

The resistance and reactance of the third and fourth branch are separately expressed as: 


$$
\begin{aligned}
& Z_{\mathrm{ifRu}}^{\prime}=\frac{R_{\mathrm{sfRu}}}{\left(1+\frac{C_{\mathrm{dfRu}}}{C_{\mathrm{sfRu}}}\right)^{2}+\left(\omega C_{\mathrm{dfRu}} R_{\mathrm{sfRu}}\right)^{2}} \\
& \text { and } \mathrm{Z}_{\mathrm{jRRu}}^{\prime}=\frac{\frac{1}{\omega C_{\mathrm{sfRu}}}\left(1+\frac{C_{\mathrm{dfRu}}}{C_{\mathrm{sfRu}}}\right)+\omega C_{\mathrm{dfRu}} R_{\mathrm{sfRu}}^{2}}{\left(1+\frac{C_{\mathrm{dfRu}}}{C_{\mathrm{sfRu}}}\right)^{2}+\left(\omega C_{\mathrm{dfRu}} R_{\mathrm{sfRu}}\right)^{2}} \\
& \text { P }
\end{aligned}
$$

Figure 2. The equivalent circuit for supercapacitor composed of composite electrodes

It is known that $R_{\mathrm{s}}=R_{\mathrm{ct}}+\frac{\sigma}{\sqrt{\omega}}, R_{\mathrm{ct}}=\frac{R T}{n F i_{o}}, C_{\mathrm{s}}=\frac{1}{\sigma \sqrt{\omega}}$, $\sigma=\frac{1}{n F A \sqrt{2}}\left(\frac{\beta_{\mathrm{ox}}}{\sqrt{D_{\mathrm{ox}}}}-\frac{\beta_{\mathrm{rd}}}{\sqrt{\mathrm{D}_{\mathrm{rd}}}}\right), \quad \beta_{\mathrm{ox}}=\frac{\mathrm{RT}}{\mathrm{nFC}_{\mathrm{ox}}^{\mathrm{b}}}, \quad \beta_{\mathrm{rd}}=-\frac{\mathrm{RT}}{\mathrm{nFC}_{\mathrm{rd}}^{\mathrm{b}}}$, $i_{\mathrm{o}}=n F A k\left(C_{\mathrm{ox}}^{\mathrm{b}}\right)^{1-\alpha}\left(C_{\mathrm{Rd}}^{\mathrm{b}}\right)^{\alpha}$

Where Rct: charge transmission resistance; $\mathrm{n}$ : charge shift number; F: Faraday constant; i0: transfer current; Coxb and $\mathrm{Crdb}$ are the oxide and the reducer concentration of the solution. Due to the area and thickness of each electrode are uniform, the electrolyte concentration is steady and the oxide and reducer concentrations of the solution are steady, $\beta$ ox, $\beta r d$, Dox, Drd can be seen as constant. If the variation of the double layer capacitance is along with potential, the double layer capacitance is proportion to the electrode area. It is supposed that the electrode thickness is d, the electrode area is A, the area of $\mathrm{RuO} 2 \cdot \mathrm{xH} 2 \mathrm{O}$ in composite electrode is $\mathrm{AfRu}$, the area of active carbon in composite electrode is AfC, the density of $\mathrm{RuO} 2 \cdot \mathrm{xH} 2 \mathrm{O}$ and active carbon are $\rho \mathrm{Ru}, \rho \mathrm{C}$. It can be obtained from the following two equations, respectively.

$$
\begin{gathered}
\frac{R_{\mathrm{ctC}}}{R_{\mathrm{ctC}}}=\frac{\sigma_{\mathrm{ctC}}}{\sigma_{\mathrm{ctrC}}}=\frac{C_{\mathrm{sfC}}}{C_{\mathrm{sC}}}=\frac{C_{\mathrm{dfC}}}{C_{\mathrm{dC}}}=\frac{A_{\mathrm{fC}}}{A}=\frac{(1-\alpha) \rho_{\mathrm{Ru}}}{(1-\alpha) \rho_{\mathrm{Ru}}+\rho_{\mathrm{C}} \alpha} \\
\frac{R_{\mathrm{ctRu}}}{R_{\mathrm{ctRu}}}=\frac{\sigma_{\mathrm{ctRu}}}{\sigma_{\mathrm{ctRu}}}=\frac{C_{\mathrm{sfRu}}}{C_{\mathrm{sRu}}}=\frac{C_{\mathrm{dfRu}}}{C_{\mathrm{dRu}}}=\frac{A_{\mathrm{fRu}}}{A}=\frac{\alpha \rho_{\mathrm{C}}}{(1-\alpha) \rho_{\mathrm{Ru}}+\alpha \rho_{\mathrm{C}}}
\end{gathered}
$$

Because the areas and thicknesses of composite electrodes are uniform, it can be supposed that the electrolyte resistances of composite electrodes is same, namely $R \Omega f=R \Omega c=R \Omega R u$. It can be reduced that the impedances of the active carbon and $\mathrm{RuO} 2 \cdot \mathrm{xH} 2 \mathrm{O}$ of composite electrodes are respectively the proportion to the pure active carbon and $\mathrm{RuO} 2 \cdot \mathrm{xH} 2 \mathrm{O}$ electrodes. Submitting (12) and (13) into (8) (11):

$$
\frac{Z_{\mathrm{icc}}^{\prime}}{Z_{\mathrm{ic}}-R_{\Omega}}=\frac{Z_{\mathrm{ifc}}^{\prime}}{Z_{\mathrm{ic}}^{\prime}}=\frac{Z_{\mathrm{jCC}}^{\prime}}{Z_{\mathrm{jC}}}=\frac{A_{\mathrm{fC}}}{A}
$$

and $\frac{Z_{\mathrm{ifRu}}^{\prime}}{Z_{\mathrm{iRu}}-R_{\Omega}}=\frac{Z_{\mathrm{ifRu}}^{\prime}}{Z_{\mathrm{iRu}}^{\prime}}=\frac{Z_{\mathrm{jfRu}}^{\prime}}{Z_{\mathrm{jRu}}}=\frac{A_{\mathrm{fRu}}}{A}$

Therefore, the resistance and reactance of composite electrodes can be obtained by the following two equations, respectively:

$Z_{\mathrm{if}}=R_{\Omega}+\frac{\left[(1-\alpha) \rho_{\mathrm{Ru}}+\rho_{\mathrm{C}} \alpha\right]^{2} Z_{\mathrm{ic}}^{\prime} Z_{\mathrm{iRu}}^{\prime}}{\left[(1-\alpha) \alpha \rho_{\mathrm{Ru}} \rho_{\mathrm{C}}+\rho_{\mathrm{C}}^{2} \alpha^{2}\right] Z_{\mathrm{ic}}^{\prime}+\left[(1-\alpha) \alpha \rho_{\mathrm{Ru}} \rho_{\mathrm{C}}+(1-\alpha)^{2} \rho_{\mathrm{Ru}}{ }^{2}\right] Z_{\mathrm{iRu}}^{\prime}}$

and

$$
Z_{\mathrm{jf}}=\frac{\left[(1-\alpha) \rho_{\mathrm{Ru}}+\rho_{\mathrm{C}} \alpha\right]^{2} Z_{\mathrm{jc}} Z_{\mathrm{jRu}}}{\left[(1-\alpha) \alpha \rho_{\mathrm{Ru}} \rho_{\mathrm{C}}+\rho_{\mathrm{C}}{ }^{2} \alpha^{2}\right] Z_{\mathrm{jc}}+\left[(1-\alpha) \alpha \rho_{\mathrm{Ru}} \rho_{\mathrm{C}}+(1-\alpha)^{2} \rho_{\mathrm{Ru}}{ }^{2}\right] Z_{\mathrm{jRu}}}
$$

In terms of (3), (16), (17), it can deduce the relationships $\alpha$ with real resistance, imaginary impedance and capacitance.

\section{RESULTS AND DISCUSSION}

In order to review the variety of resistance and capacitance of super-capacitors at different ratios $\alpha$, it need to measure the Impedance Spectroscopy of the super-capacitors fabricated with pure active carbon and pure $\mathrm{RuO}_{2} \cdot x \mathrm{H}_{2} \mathrm{O}$ electrodes, respectively, as seen in Fig.3 curve $\mathrm{A}, \mathrm{F}$. In order to observe the variety rule of inner resistances of super-capacitor with $\alpha$, it is observed that the change curve of real resistance by (16) at $1.758 \times 10^{4} \mathrm{~Hz}, Z_{\mathrm{j}} \approx 0$; The repeat frequency of charge and discharge used in pulse power source is usually around 0 $100 \mathrm{~Hz}$, so it selects the resistance of super-capacitor at $f=1 \mathrm{~Hz}$ and calculated the variety rule of capacitances of composite electrodes at different ratios $\alpha$ by (3). Table.I is the data involved in models parameters in equations.

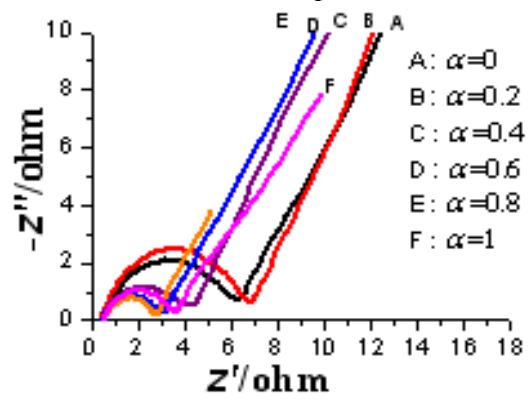

Figure 3. Impedance characteristics of composite electrodes

TABLE I. PARAMETERS THAT DESCRIBE THE COMPOSITE ELECTRODE

\begin{tabular}{ccc}
\hline Parameter & Value & Ref. \\
\hline $\mathrm{R} \Omega$ & $0.3 \Omega$ & Assumed \\
$\rho \mathrm{C}$ & $1.09 \mathrm{~g} / \mathrm{cm} 3$ & Factory \\
$\rho \mathrm{Ru}$ & $0.5 \mathrm{~g} / \mathrm{cm} 3$ & measured \\
$\mathrm{Zic}(\mathrm{f}=1 \mathrm{~Hz})$ & $0.7586 \Omega$ & measured \\
$\mathrm{ZiRu}(\mathrm{f}=1 \mathrm{~Hz})$ & $0.3987 \Omega$ & measured \\
$\mathrm{Zjc}(\mathrm{f}=1 \mathrm{~Hz})$ & $-1.8120 \Omega$ & measured \\
$\mathrm{ZiRu}(\mathrm{f}=1 \mathrm{~Hz})$ & $-0.8882 \Omega$ & measured \\
$\mathrm{Zic}(\mathrm{f}=1.76 \times 104 \mathrm{~Hz})$ & $0.3819 \Omega$ & measured \\
$\mathrm{ZiRu}(\mathrm{f}=1.76 \times 104 \mathrm{~Hz})$ & $0.4872 \Omega$ & measured \\
\hline
\end{tabular}

In Fig.4 the solid line is relationship of $Z_{\mathrm{if}}^{\prime}(\omega)$ calculated by (14) and $\alpha$ at $1.758 \times 10^{4} \mathrm{~Hz}$; the dot is the resistances at different ratios $\alpha$ at $1.758 \times 10^{4} \mathrm{~Hz}$. From the simulation results, in $\alpha=[1,0.6], Z_{\text {if }}(\omega)$ descends rapidly and the resistance of composite electrodes changes evidently; In the range of $[0.6,0], Z_{\text {if }}(\omega)$ drops slowly, the 
change is not big. It is obvious that in the range $[0.6,1]$ reducing the resistance of electrodes has obvious effect. From Fig.3, the above result is also proved, we can see, that after adding to the active carbon, the inner resistance of super-capacitor minishes along with the $\alpha$, Faraday impedance circularity of pure $\mathrm{RuO}_{2} \cdot x \mathrm{H}_{2} \mathrm{O}$ is smaller than of pure active carbon, namely charge transmission resistance $\mathrm{R}_{\mathrm{ct}}$ of pure $\mathrm{RuO}_{2} \cdot x \mathrm{H}_{2} \mathrm{O}$ is smaller than of pure active carbon, but when $\alpha=0.4,0.6,0.8$, Faraday resistance circularity of them is smaller than of pure $\mathrm{RuO}_{2} \cdot x \mathrm{H}_{2} \mathrm{O}$. It shows that pore active carbon adhere to $\mathrm{RuO}_{2} \cdot x \mathrm{H}_{2} \mathrm{O}$ after adding to active carbon, the pores of electrodes and the electrolyte inside the pores of the electrodes increases, as a result the contact resistant between the particles of electrodes minishes to decrease the inner resistance of composite electrodes. On the other hand, when the proportion of the active carbon is not big, as the ions of electrolyte inside the pores of the electrodes is in favor of the transmission of the charge and the concentration of reactant increases, the charge transmission resistance decreases, but when the proportion of active carbon is bigger than a certain value, active carbon of the electrodes takes the main action to increase the charge transmission resistance.

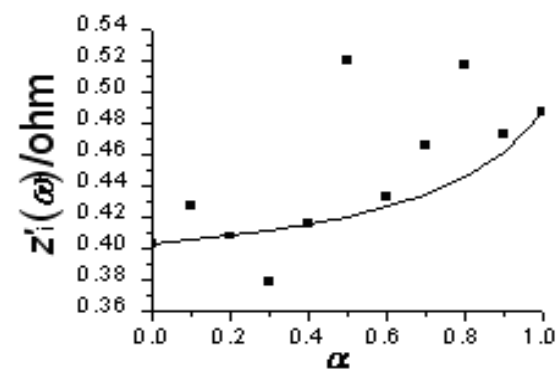

Figure 4. At $1.76 \times 104 \mathrm{~Hz}$, the relation of $Z^{\prime} i(\omega)$ and $\alpha$ : the solid line is the simulation data, the dots is the actual data

In Fig.5, the solid line is the calculated relationship of $C(\omega)$ and $\alpha$ at $1 \mathrm{~Hz}$; the dot is the measured data at $1 \mathrm{~Hz}$ at different $\alpha$. As seen in Fig.5, $C(\omega)$ approximately minishes linearly along with increasing the active carbon. When $\alpha=$ $0,0.2,0.4,0.6,0.8,1$, the discharge curve of composite electrodes at $3 \mathrm{~mA}$ constant current can be seen in Fig.6. In terms of the calculated equation, the specific capacitances are respectively: $131 \mathrm{~F} / \mathrm{g}, 230 \mathrm{~F} / \mathrm{g}, 345 \mathrm{~F} / \mathrm{g}, 567 \mathrm{~F} / \mathrm{g}, 667 \mathrm{~F} / \mathrm{g}$, $776 \mathrm{~F} / \mathrm{g}$, and when $\alpha=0.1,0.3,0.5,0.7$, and 0.9 that cannot be seen in Fig.5, the specific capacitances are: 160F/g, $289 \mathrm{~F} / \mathrm{g}, 436 \mathrm{~F} / \mathrm{g}, 587 \mathrm{~F} / \mathrm{g}$ and $692 \mathrm{~F} / \mathrm{g}$. For the variety of specific capacitance, it shows that when the content of $\mathrm{RuO}_{2} \cdot x \mathrm{H}_{2} \mathrm{O}$ is low, the grains of $\mathrm{RuO}_{2} \cdot x \mathrm{H}_{2} \mathrm{O}$ are almost covered by the particles of active carbon, and composite electrodes represent the nature of active carbon; When the content of $\mathrm{RuO}_{2} \cdot x \mathrm{H}_{2} \mathrm{O}$ increase gradually, the effects of $\mathrm{RuO}_{2} \cdot x \mathrm{H}_{2} \mathrm{O}$ strengthen. For the capacitance of $\mathrm{RuO}_{2} \cdot x \mathrm{H}_{2} \mathrm{O}$ is decuple higher than that of active carbon, the specific capacitance of composite electrodes increase rapidly along with increasing the content of $\mathrm{RuO}_{2} \cdot x \mathrm{H}_{2} \mathrm{O}$.

Therefore, it can be seen that the $\mathrm{RuO}_{2} \cdot x \mathrm{H}_{2} \mathrm{O}$ mass ratio of composite electrode $\alpha=0.6$ is perfect from the results of the simulation and experiments, that minishes the inner resistance as ensuring the high specific capacitance.

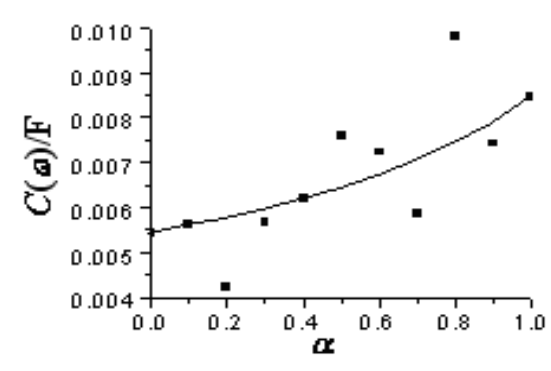

Figure 5. At $1 \mathrm{~Hz}$, the relation of $\mathrm{C}(\omega)$ and $\alpha$ : the solid line is the simulation data, the dots is the actual data

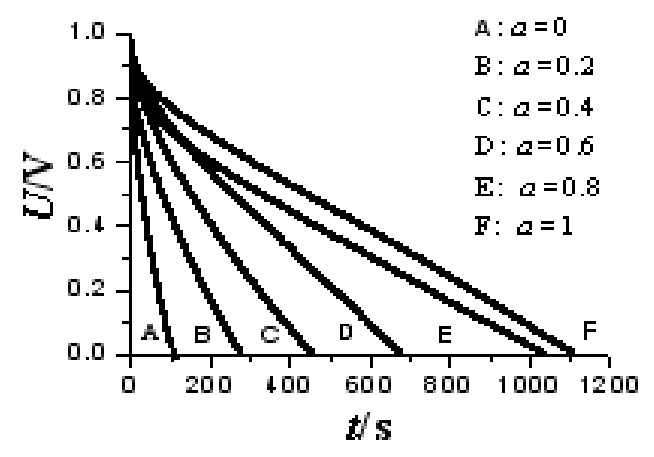

Figure 6. Discharge curves of composite electrodes

\section{CONCLUSION}

In this paper, $\mathrm{RuO} 2 \cdot \mathrm{xH} 2 \mathrm{O} /$ active carbon composite electrodes for hybrid super-capacitor is studied. The relationships of the resistance and capacitance with the mass ratio $\alpha$ of $\mathrm{RuO} 2 \cdot \mathrm{xH} 2 \mathrm{O}$ in the composite electrode that is made of $\mathrm{RuO} 2 \cdot \mathrm{xH} 2 \mathrm{O}$ powder and active carbon, is analyzed. The simulation and experiment results show that adding active carbon into $\mathrm{RuO} 2 \cdot \mathrm{xH} 2 \mathrm{O}$ can improve the impedance of composite electrodes, but reduce the specific capacitance. Considered the above aspects, when the mass ratio of ruthenium oxide is about $60 \%$, the specific capacitance of composite electrodes is $567 \mathrm{~F} / \mathrm{g}$ and the inner resistance is $0.4331 \Omega$.

\section{ACKNOWLEDGMENT}

This work was funded in part by a grant from National Natural Science Foundation of China No. 5307012. This work was also partly supported by the fund of Liaoning Province Doctor Startup, NO.20131009 and the Dalian Ocean University Doctor Starup, No. HDYJ201302.

\section{REFERENCES}

[1] D.H. Seo, Z.J. H, S. Kumar and K. Ostrikov, "Structure-Controlled, Vertical Graphene-Based, Binder-Free Electrodes from PlasmaReformed Butter Enhance Supercapacitor Performance," Adv. Energy Mater, vol. 3, 2013, pp. 1316-1323.

[2] P. Sharma and T.S. Bhatti, "A review on electrochemical doublelayer capacitors," Energy Conversion and Management, vol. 51, 2010, pp. 2901-2912.

[3] K. Wang, L. Zhang, B.C. Jin, and J.L. Yuan, "The thermal analysis on the stackable supercapacitor," Energy, vol. 59, 2013, pp. 440444

[4] M. Beidaghi and Y. Gogotsi, "Capacitive energy storage in microscale devices:recent advances in design and fabrication of microsupercapacitors," Energy \& Environmental Science, vol. 7, 2014, pp. 867-5-884. 
[5] K. Wang, C. L, B.C. Ji, “ Preparation of electrode Based on Plasma Modification and its Electrochemical Application," Journal of Materials Engineering and Performance, vol. 23, 2014, pp. 588-592.

[6] K. Wang and L. Zhang, "Synthesis of ordered mesoporous carbon and its electrochemical performances," International Journal of Electrochemical Science, vol. 8, 2013, pp. 2892-2897.

[7] Z.Q. Dai, K. Wang, L.W. Li and T.Z. Zhang, "Synthesis of nitrogen-doped graphene with microwave," International Journal of Electrochemical Science, vol. 8, 2013, pp. 9384-9389.

[8] W. Yang, Z. Gao, J. Ma, X.M. Zhang, J. Wang and J.Y. Liu, "Hierarchical NiCo2O4 @ NiO core-shell heterostructured nanowire arrays on carbon cloth for a high-performance flexible all-solid-state electrochemical capacitor," Journal of Materials Chemistry, vol. 2, 2014, pp. 1448-1457.

[9] J. Xu, Q. Wang, X. Wang, Q.Y. Xiang, B. Liang, D. Cheng and G.Z. Shen, "Flexible Asymmetric Supercapacitors Based upon Co9S8 Nanorod//Co3O4@ RuO2 Nanosheet Arrays on Carbon Cloth," ACS Nano, vol. 7, 2013, pp. 5453-5462.

[10] K. Wang, L. Li and T. Zhang, "Synthesis of nickel hydroxide and its electrochemical performances," International Journal of Electrochemical Science, vol. 8, 2013, pp. 6252-6257.

[11] C. Zhou, Y.W. Zhang, Y.Y. Li and J.P. Liu, "Construction of High -Capacitance 3D CoO @ Polypyrrole Nanowire Array Electrode for Aqueous Asymmetric Supercapacitor," Nano Letter, vol. 13, 2013, pp. 2078-2085.

[12] K. F. Babu, S. P. Siva Subramanian and M. A. Kulandainathan, "Functionalisation of fabrics with conducting polymer for turning capacitance and fabrication of supercapacitor," Carbohydrate Polymers, vol. 94, 2013, pp. 487-495.

[13] C. Zhou, Y.W. Zhang, Y.Y. Li and J.P. Liu, "Construction of High-capacitance 3D CoO@Polypyrrole Nanowire Array Electrode for Aqueous Asymmetric Supercapacitor," Nano Letter, vol. 13, 2013, pp. 2078-2085.

[14] K.M. Kim, J.H. Nam, Y.G. Lee, W.L. Cho and J.M. Ko, "Supercapacitive properties of electrodeposited $\mathrm{RuO} 2$ electrode in acrylic gel polymer electrolytes," Current Applied Physics, vol. 13, 2013, pp. 1702-1706

[15] L. Zhang, J.Y. Song, and J.Y. Zou, "Electrochemical Property of Ru-Mn-AC Multi-Element Composite Electrode Materials," Rare Metal Materials and Engineering, vol. 38, 2009, pp. 11-14.

[16] H. Ashassi-sorkhabi, E. Asghari and P. Badakhshan, "Potentiostatic and cyclic voltammetric deposition of nanostructured manganese oxide for supercapacitor applications," Current Applied Physics, vol. 14, 2014, pp. 187-191.
[17] K. Wang, L. Zhang, Y.H. Jin and Y. Fan, "The preparation of nickel oxide based on infinite dilute method and its electrochemical performance," Russian Journal of Electrochemistry, vol. 50, 2014, pp. 192-196

[18] H.T. Fang, M. Liu, D.W. Wang, X.H. Ren and X. Sun, "Fabrication and supercapacitive properties of a thick electrode of carbon nanotube- $\mathrm{RuO} 2$ core-shell hybrid material with a high RuO2 loading," Nano Energy, vol. 2, 2013, pp. 1232-1241.

[19] K. Wang, L. Li and X.Wu, "Synthesis of active carbon and ruthenium oxide for electrochemical performance," International Journal of Electrochemical Science, vol. 8, 2013, pp. 6574-6578.

[20] P.C. Chen, S.J. Hsieh, J. Zou, and C.C. Chen, "Selectively dealloyed $\mathrm{Ti} / \mathrm{TiO} 2$ network nanostructures for supercapacitor application," Materials Letters, vol. 133, 2014, pp. 175-178.

[21] X. Liu, J. Zhu, X. Wang, J. Sun, Z. Tang, T. Zhang and M.J.O, "Capacitive Properties and Structure of RuO2-HfO2 Films Prepared by Thermal Decomposition," Method.Physics Procedia, vol. 50, 2013, pp. 416-420.

[22] S.N. Pusawale, P.R. Deshmukh, J.L. Gunjakar and C.D. Lokhande, "SnO2-RuO2 composite films by chemical deposition for supercapacitor application," Materials Chemistry and Physics, vol. 139, 2013, pp. 416-422.

[23] J.Y. Zou, L. Zhang and J.Y. Song, "Development of the 40V Hybrid Supercapacitor Unit," IEEE transation on magnetics, vol. 41, 2005, pp. 294-298.

[24] J.Y. Song, L. Zhang and Z.J. Zou, "Investigations on Increasing the Operation Voltage of Hybrid Supercapacitors used in Pulsed Power System," 18th IEEE PPC, 2011, pp. 717-720.

[25] S. Faraji and F.N. Ani, "Microwave-assisted synthesis of metal oxide/hydroxide composite electrodes for high power supercapacitors - A review", Journal of Power Sources, vol. 263 2014, pp. 338-360.

[26] V. Barsukov and S. Chivikov, "The "capacitor" concept of the current-producing mechanism in polyaniline-type conducting polyers," Electrochimica Acta, vol 41, 1996, pp. 1773-1779

[27] R.P. Simpraga and B.E. Conway, "The real-area scaling factor in electrocatalysis and in charge storage by supercapacitors," Electrochimica Acta, vol. 43, 1998, pp. 3045-3058.

[28] K. Wang, L. Zhang, B. Ji and J. Yuan, "The thermal analysis on the stackable supercapacitor," Energy, vol. 59, 2013, pp. 440-444.

[29] A. Eddahech, O. Briat, M. Ayadi and J.M. Vinassa, "Modeling and adaptive control for supercapacitor in automotive applications based on artificial neural networks," Electric Power Systems Research, vol. 106, 2014, pp. 134-141. 